This item was submitted to Loughborough's Research Repository by the author.

Items in Figshare are protected by copyright, with all rights reserved, unless otherwise indicated.

\title{
Fracture process in cortical bone: X-FEM analysis of microstructured models
}

PLEASE CITE THE PUBLISHED VERSION

http://dx.doi.org/10.1007/s10704-013-9814-7

\section{PUBLISHER}

(c) Springer Science and Business Media

\section{VERSION}

AM (Accepted Manuscript)

\section{LICENCE}

CC BY-NC-ND 4.0

\section{REPOSITORY RECORD}

Li, Simin, Adel A. Abdel-Wahab, Emrah Demirci, and Vadim V. Silberschmidt. 2019. "Fracture Process in Cortical Bone: X-FEM Analysis of Microstructured Models". figshare. https://hdl.handle.net/2134/14238. 
This item was submitted to Loughborough's Institutional Repository (https://dspace.lboro.ac.uk/) by the author and is made available under the following Creative Commons Licence conditions.

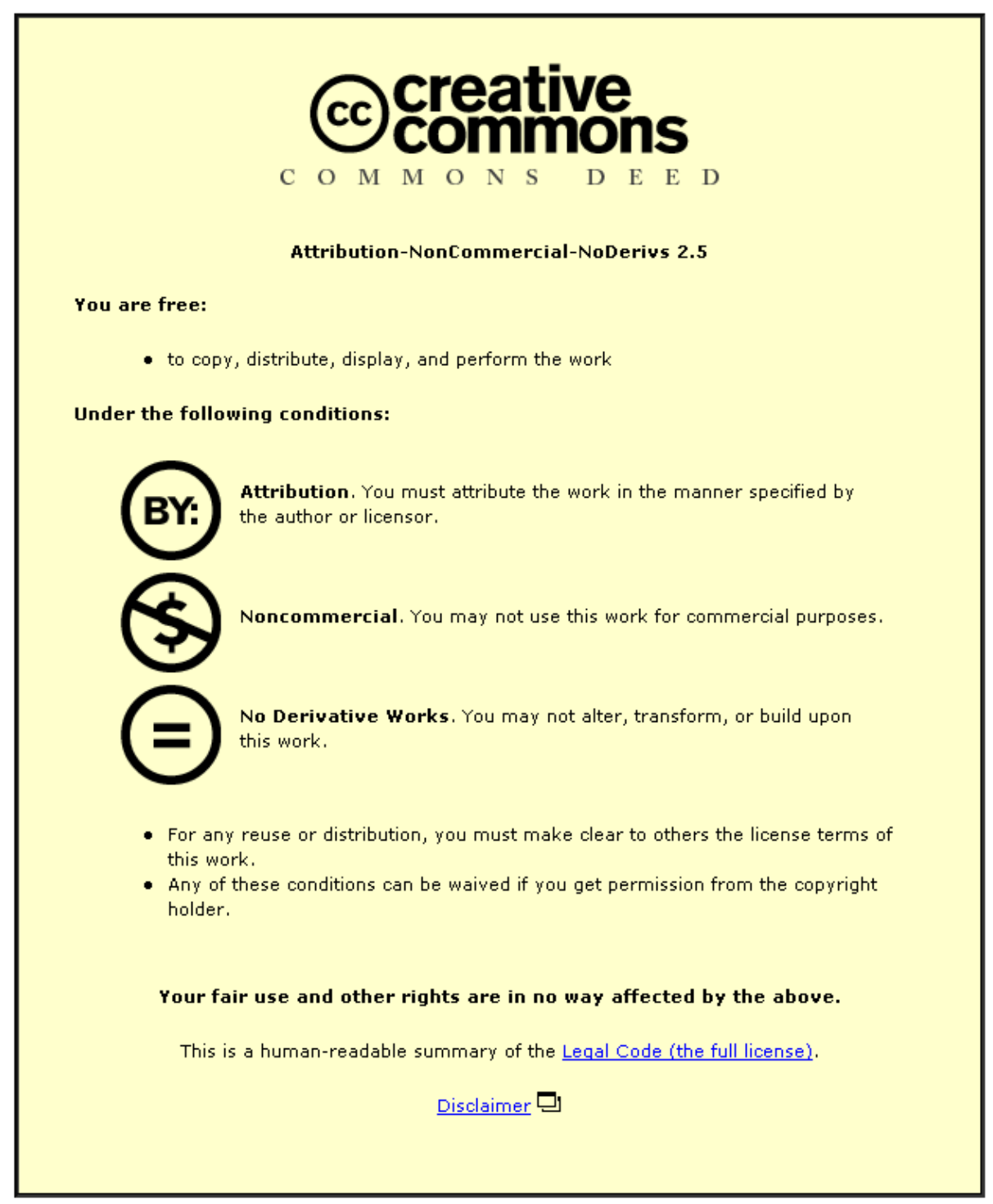

For the full text of this licence, please go to: http://creativecommons.org/licenses/by-nc-nd/2.5/ 


\title{
Fracture process in cortical bone: X-FEM analysis of microstructured models
}

\author{
Simin $\mathrm{Li}^{1}$, Adel Abdel-Wahab ${ }^{2}$, Emrah Demirci ${ }^{3}$ and Vadim V. Silberschmidt ${ }^{4^{*}}$ \\ Wolfson School of Mechanical and Manufacturing Engineering, Loughborough \\ University, Loughborough, Leicestershire, LE11 3TU, UK \\ ${ }^{1}$ S.Li@lboro.ac.uk, ${ }^{2}$ A.A.Abdel-wahab@lboro.ac.uk, ${ }^{3}$ E.Demirci@lboro.ac.uk, \\ 4*V.Silberschmidt@lboro.ac.uk
}

\begin{abstract}
Bones tissues are heterogeneous materials that consist of various microstructural features at different length scales. The fracture process in cortical bone is affected significantly by the microstructural constituents and their heterogeneous distribution. Understanding mechanics of bone fracture is necessary for reduction and prevention of risks related to bone fracture. The aim of this study is to develop a finite-element approach to evaluate the fracture process in cortical bone at micro-scale. In this study, three microstructural models with various random distributions based on statistical realizations were constructed using the global model's framework together with a submodelling technique to investigate the effect of microstructural features on macroscopic fracture toughness and microscopic crack-propagation behaviour. Analysis of processes of crack initiation and propagation utilized the extended finite-element method (X-FEM) using energybased cohesive-segment scheme. The obtained results were compared with our experimental data and observations and demonstrated good agreement. Additionally, the microstructured cortical bone models adequately captured various damage and toughening mechanisms observed in experiments. The studies of crack length and fracture propagation elucidated the effect of microstructural constituents and their mechanical properties on the microscopic fracture propagation process.
\end{abstract}

Key words: X-FEM, microstructured model, crack propagation, fracture toughening mechanisms

\section{Introduction}

Fracture of cortical bone can significantly affect structural integrity of a loadbearing skeletal system, and, consequently, cause injuries, mobility loss and reduced life quality. As a naturally formed composite material, a cortical bone tissue is formed by heterogeneously distributed microstructural constituents that could be categorised into several hierarchical organizations from nano-scale to macro-scale levels (Currey 2011; Ritchie et al. 2005). At the nano-scale, bone is composed of mineralized collagen fiber matrix and extrafibrillar mineral 
particles known as carbonated hydroxyapatite (Currey 1999; Fratzl et al. 2004). At the micro-scale, cortical bone is laid down in layers of lamellar structure (3-7 $\mu \mathrm{m}$ in thickness) that is similar to that of plywood composite - parallel with each other within layer, but having a staggered arrangement between the adjacent layers (Ascenzi and Benvenuti 1986). Across a bone section, concentric layers of lamellae together with hollowed vascular channels form the most observable structure under microscope - a Haversian system (containing osteon and a Haversian canal) embedded into the remnants of a bone's remodelling process called interstitial matrix. Osteons are, on average, a $200 \mu \mathrm{m}$ in diameter and up to $1 \mathrm{~cm}$ long cylindrical structure parallel to the bone's longitudinal axis (Ethier and Simmons 2007). In addition, a network of canals and channels formed across the bone's section accommodates blood vessels and a nervous system; those large canals, on average 50-90 $\mu \mathrm{m}$ in diameter, parallel to the bone's main axis are called Haversian canals. Bone has living cells called osteocytes that live within an interconnected network of microscopic channels called canaliculi. The latter are responsible for exchange of nutrients and waste between osteocytes (Ethier and Simmons 2007).The interface between osteons and interstitial matrix is called cement line; it is $2-5 \mu \mathrm{m}$ in thickness. It plays a key role in the bone's mechanical behaviour, especially its fracture. However, the opinions in the literature with regard to the mechanical properties of cement line are rather controversial. Different experimental observations reported that the cement line can act either as a toughening mechanism deflecting a crack from osteons or as a weakening path that facilitates the crack initiation (Currey 2011; Ritchie et al. 2005). At the millimetre length scale, the dense and thick outer layer of cortical bone and the porous sponge-like trabecular bone make up the tissue-level bone structure (Peterlik et al. 2006). All these hierarchical levels work together in accord and complementing each other to achieve enhanced macroscopic mechanical properties of the bone tissue at the full-bone scale (Peterlik et al. 2006).

The micro-architecture of cortical bone has a significant effect on its mechanical and fracture properties. Moreover, preferential alignment of both collagen fibrils and mineral crystals at nano-scale and the osteons and Haversian cannals at 
micro-scale results in highly anisotropic mechanical and fracture behaviour of the tissue (Peterlik et al. 2006). The anisotropic ratio of fracture toughness for different crack propagation directions can be significantly large - from 2 to $3-$ depending on interaction of a propagating crack with the microstructural features, activation of various toughening mechanisms affecting fracture resistance: formation of microcracks in the vicinity of the main crack due to stress concentrations ahead of its tip (Vashishth et al. 2003; Zioupos and Currey 1994; Zioupos et al. 1996) and crack deflection and blunting at cement lines that create discontinuity at the boundary layers (Liu et al. 1999). Recently, it was reported that ligament bridging of crack in the wake zone is a dominant toughening mechanism in cortical bone as it reduces a driving force at the crack tip (Nalla et al. 2004; 2003; 2005). Several authors reported that toughening mechanisms are highly dependent on a crack propagation direction; therefore, fracture toughness of long bones is significantly higher in transverse and radial directions compared to the longitudinal one (Behiri and Bonfield 1989; Martin and Boardman 1993; Nalla et al. 2005).

Being a physiological living tissue, bone has the ability of continuously remodelling, repairing and adapting itself to the surrounding environment. Due to this inherent dynamics, both the microstructure of cortical bone and its mechanical behaviour vary dramatically from one part to another. Considering differences introduced by using various test methods and specimen's sizes, the spectrum of fracture energy per unit area of cortical bone varies from $920 \mathrm{~N} / \mathrm{m}$ to $2780 \mathrm{~N} / \mathrm{m}$ (Ritchie et al. 2005) for the same type of bone tested at same orientation. This variability is significant even for different cortices of a single bone (Bonney et al. 2011). Unlike traditional artificial composite materials, which have predefined average volume fraction and, consequently, a limited range of their mechanical properties, the volume fraction of each constituent of cortical bone is not unique and changes during the bone remodelling process. As a result, the randomly distributed elements of microstructure at the local region have a significant impact on variability of the mechanical behaviour of cortical bone at macro-scale level. However, a rather small number of studies was performed to unveil a correlation between the variation of microstructure and variability of the mechanical behaviour of cortical bone. 
Finite-element simulations provide a powerful tool to analyse the fracture behaviour of materials at different length scales. Ural and Vashishth (Ural and Vashishth 2006) developed a cohesive-zone-element model to capture an experimentally observed rising crack-growth behaviour and age-related loss of bone toughness. Later, the same authors investigated the effects of age-related changes and orientation of crack growth on a toughening behaviour of human cortical bone using the same model. The used approach - cohesive-zone (CZ) method - accounts for the nonlinear fracture mechanism and describes the nonlinear fracture process in terms of a traction-separation law; it has been broadly used in the literature (Ural et al. 2011; Yang et al. 2006) to investigate the fracture mechanics of cortical bone. However, it has an inherent drawback: the crack extension has to follow a predefined path around elements of the mesh. Obviously, in the case of fracture of real bones such a crack path is hard to predict. Similar to the $\mathrm{CZ}$ technique, an analytical approach based on perturbation technique were recently extended by Piccolroaz et al. (Piccolroaz et al. 2012) to solve an interfacial crack problem in heterogeneous material where a crack path was assumed coincide with a bonding interface between dissimilar materials. The extended finite-element method ( $X$ FEM) was used in a small number of papers on fracture in bones to overcome this issue. For instance, Budyn and Hoc (Budyn and Hoc 2007) introduced a multi-scale method to simulate multiple crack growth in a cortical bone tissue using X-FEM under simplified tensile loading conditions. In another recent attempt, Liu et al. (Liu et al. 2010) developed a homogenised X-FEM model to predict fracture of a proximal femur due to impact. Despite many attempts by various researchers, the model development for fracture of cortical bone is still limited to simplified formulations: simplified material properties; a microstructured model with applied linear-elastic material properties and boundary conditions for a very small region (less than $1 \mathrm{~mm}$ in length) (Budyn and Hoc 2007); a fullsize bone model but with continuum homogenised material properties (Liu et al. 2010). There is still a need in a comprehensive X-FEM model that can reflect adequately the main features characteristic to the bone fracture process. 
Therefore, in this paper, a microstructured model of cortical bones is proposed to study the effect of its microstructure on variability of fracture toughness and crack-propagation process for the case of three-point bending, typical for experimental fracture analysis.

\section{Materials and methods}

\section{Modelling approach}

To investigate the variability of fracture toughness and various toughening mechanisms induced by random microstructure, three two-dimensional microstructured models of cortical bone were developed in commercial finiteelement software - Abaqus (Dassault Systèmes 2012). The models were established based on configuration of our three-point-bending experiments detailed in (Li et al. 2012). These models were constructed using a submodelling technique that focuses the computational power at the crack-propagation region while maintaining the full-scale approach of the model. The submodelling technique allows development of multiple models based on the same modelling object and extends the level of interest into a pre-defined region (usually with a finer mesh or more local geometric details) to achieve adequate and accurate results. The computational cost of submodelling technique is usually lower when compared with the whole-size model having the same level of accuracy. The developed approach employed two different levels of modelling of the bone tissue: full size global model for the macroscopic response of the entire specimen under three-point bending and three submodels reflecting microscopic responses of different localized microstructures during the crack propagation process. The boundary conditions in the submodel were derived for the correspondent region from the results of the global model using the displacement-control criterion based on the nodal field variables.

The model geometries correspond to those of the specimens used in our experiment: $25 \mathrm{~mm} \times 2.72 \mathrm{~mm} \times 5.43 \mathrm{~mm}$ (total length $\times$ width $\times$ thickness). Cylindrical loading pins at the three-point setup were modelled as analytical rigid bodies with a radius of $5 \mathrm{~mm}$. The span (length between the centres of two holding pins) and the pre-crack length were chosen according to the experimental setup: $21.72 \mathrm{~mm}$ and $2.72 \mathrm{~mm}$, respectively. Then, the submodel was extruded 
from the central un-cracked region of the global model with dimension of 2.72 $\mathrm{mm} \times 2.72 \mathrm{~mm}$ (Fig. 1). The pre-crack is mostly outside the submodel with only one element of its bottom middle surface cut by it.

\section{Model configuration}

The random microstructural distributions inside the submodels were constructed as four-phase composite structures consisting of interstitial bones (i) and Haversian systems that include osteons (ii), Haversian canals (iii) and cement line (iv). All geometrical parameters of each model were defined based on statistical analysis of real microstructures (for details see (Abdel-Wahab et al. 2010b)) obtained with optical microscopy of radial-transverse sections from a lateral cortex where a large portion of osteonal structure can be observed. That analysis confirmed the volumetric fraction of osteons in the range from $28 \%$ to $55 \%$. The porosity ratio was measured between $5 \%$ and $13 \%$. The average width of cement line was close to $5 \mu \mathrm{m}$. The distributions of diameters of osteons and Haversian canals were regularized statistically using best-fit functions described in detail in (Abdel-Wahab et al. 2010b). The average diameters for osteons and Haversian canals were $99.89 \mu \mathrm{m}$ and $23.1 \mu \mathrm{m}$, respectively.

The algorithm to generate random microstructures in the submodels was first programed in a custom-developed Matlab code according to the statistical data for real bone specimens, and then all the geometrical parameters were encoded into a python script to construct the microstructural model in Abaqus. Three representative microstructured cortical bone models were developed and employed in this study based on the statistical measurements for each constituent: osteons volume fraction varies from $30 \%$ to $51 \%$, while porosity changes from $5 \%$ to around $8 \%$ (Fig. 2). Full data on the volume fractions of microstructure constituents used in the models are listed in Table 1.

\section{Material properties}

In this study, the mechanical behaviour of cortical bone was introduced using an elasto-plastic transverse isotropic material formulation with regard to the radialtransverse section plane (see Fig. 1). At macroscopic level, the effective homogeneous material was used in the global model neglecting microscopic heterogeneity. The effective elasto-plastic material properties obtained from our 
macroscopic experiments (Abdel-Wahab et al. 2010a) were applied in the global model. On the other hand, at microscopic level, microstructural constituents play an important role in the localized fracture process and formation of toughening mechanisms. Consequently, the four-phase microstructured models of cortical bone were employed in the submodel, and individual material properties based on nano-indentation results (Abdel-Wahab et al. 2010b) were assigned to constituents. The elastic modulus of cement line was initially set to be $25 \%$ lower than that of osteon based on the findings in (Budyn and Hoc 2007; Montalbano and Feng 2011), and two other levels - equal to that of osteon and 25\% higher were also used to investigate the effect of cement line's properties on the fracture process in cortical bone. A strain-based yield criterion was implemented both in the global model and submodels, and a yield strain of $0.6 \%$ was chosen based on (Abdel-Wahab et al. 2010a). The post-yield material behaviours in both global and sub-models were based on flow stress-strain curves obtained experimentally (Abdel-Wahab et al. 2010a; Abdel-Wahab et al. 2010b). A summary of material properties used in this study is given in Table 2.

Damage and crack propagation in this study were modelled using the X-FEM technique in Abaqus (Dassault Systèmes 2012) that allows a crack to initiate and propagate through an arbitrary, solution-dependent path subject on the local material response. Hence, the X-FEM enrichment was applied to the whole model for all the cases. The local crack initiation and evolution were evaluated continuously based on chosen criteria. Crack initiation in a hard biological tissue (cortical bone) was commonly described with a strain-driven criterion (Nalla et al. 2003). Therefore, a strain-based crack-initiation criterion was set up both in global and microstructured models. It assumes that crack initiates when the maximum principal strain reaches its critical value and the newly defined crack direction is orthogonal to that of the maximum principal strain. A crack initiation strain of $0.65 \%$ was chosen based on our observations of material response for the radialtransverse direction detailed in (Abdel-Wahab et al. 2010a). Once initiated, crack conforms to the energy-based damage evolution criterion, and the cracked element starts degradation and eventually fails. The governing formulation for the onset of crack utilizes a cohesive traction-separation constitutive behaviour to define the damage evolution of the cracked surface. It describes the rate, at which the cohesive stiffness of the cracked surface degrades once the crack-initiation 
criterion is fulfilled at particular element. The energy dissipated (fracture energy) as a result of damage progress is equal to the area under the traction-separation curve at the point of complete damage. The fracture energy in our models (Table 2) was defined according to the previous results (Abdel-Wahab et al. 2010b; Li et al. 2012; Ritchie et al. 2005).

\section{Mesh-convergence analysis}

The global model was discretised into 14,000 of four-node bilinear plane-strain quadrilateral elements and ran on an eight-processor (quad-core Intel I7 $970 \mathrm{CPU}$ ) PC while the submodels were meshed using 150,000 to 200,000 elements of the same type and ran on a 60-processors (five six-core Intel Westmere Xeon X5650 CPUs) high-performance cluster. The Abaqus implicit solver was used in both types of simulations. A mesh-convergence study was carried out for the global model using six different element sizes, and the obtained results were analysed in terms of peak reaction forces as demonstrated in Fig. 3. Apparently, the reaction force converges when the minimum element size reduces to $100 \mu \mathrm{m}$ or below. Therefore, the minimum element size for the global model was chosen to be 50 $\mu \mathrm{m}$ and the minimum element size for the submodel was around $5 \mu \mathrm{m}$.

\section{Results}

\section{Effect of microstructure on variability of fracture toughness}

Three microstructured models of cortical bone were analysed in this study. Their results are compared with that of the effective homogeneous model as well as experimental data in terms of force - displacement diagram in Fig. 4. Dissimilar fracture-resistance behaviours were evidenced for three different microstructured models. The change in the microstructure at microscopic level has a significant impact on the macroscopic fracture toughness of cortical bone. Among the three models, Model A has the highest critical value of $\mathrm{J}$ integral $-2503 \mathrm{~N} / \mathrm{m}$, while Models B and C result in 2369 N/m and 2212 N/m, respectively. This decreasing trend in the fracture resistance is apparently linked to the increasing volume fractions of osteons and porosity (Haversian canals in this case). From the morphological point of view, the bone remodelling process generates new Haversian systems (each including an osteon, a Haversian canal and a cement 
line) to replace the old, damaged regions as an adaptive process. The newly formed bone cell is usually less mineralized than its surrounding area due to the fact that mineral concentration period lasts longer than the remodelling process (Currey 2011). As a result, a large fraction of less mineralized osteons associated with the bone-mass and stiffness reduction has a negative impact on the overall fracture resistance of cortical bone. Still, benefiting from their low stiffness but high fracture toughness, osteons demonstrate a higher failure strain when compared with interstitial matrix and, in general, offer a positive effect on fracture toughness. On the other hand, the increasing proportion of Haversian system leads to the increase in structural compliance as a result of cavitation, hence, to increased overall fracture strain (Fig. 4). These mutual effects of microstructural constituents result in the variation of macroscopic fracture toughness. Significant nonlinearity observed at the initial loading stage during the experiment was successfully captured using the microstructured model. Comparing the proportion of the plastic component $\left(\mathrm{J}_{\mathrm{p}}\right)$ of the critical value of $\mathrm{J}$-integral $\left(\mathrm{J}_{\mathrm{c}}\right)$ in each model, an increased tendency for the energy associated with plastic deformation is observed for the increase of osteon and porosity volume fractions (Fig. 5). Based on the above findings, the bone remodelling process related with the increasing fraction of osteons and porosity changes the bone's fracture resistance from a stress-based mode to a more strain-based mode - fracture stress resistance reduces but fracture strain resistance increases.

\section{Heterogeneous fracture process due to microstructure}

At the global level, the effective homogeneous material model was able to capture a macroscopic response in terms of force - displacement curve (Fig. 4). However, the detailed fracture evolution process, especially the localized damage zone was neglected at this level. On the contrary, the heterogeneous models with random microstructures, operating within the framework of the global model using direct displacement-controlled boundary conditions, emphasise the effect of the local non-uniform stress-strain field on the crack propagation process at microscopic level. Figure 6 presents contour plots for von-Mises stress, maximum principal strain, equivalent plastic strain (PEEQ) and a damage scale factor for X-FEM (STATUS) for Model B when the crack is approaching the state of the maximum reaction force. As evidenced from the figure, a diffused stress pattern is 
characteristic for the von-Mises contour, while a cross-hatched strain pattern for the maximum principal strain contour is located ahead of the crack tip (in the compressive region of the specimen) with a diffused strain pattern near it (in the tensile region). These dissimilar stress and strain patterns around the crack tip coincide with results of the previous experimental studies (Boyce et al. 2005; Ebacher and Wang 2008; Nyman et al. 2009), in which the authors indicated that such distinctive stress and strain fields in tension and compressive regions could lead to realization of different damage fracture mechanisms. Equivalent plastic strain illustrated in Fig. 6-c indicates that the area undergoes plastic deformation during the crack propagation process. The identified plastic zone around the crack tip is within $1-2$ osteonal radius i.e. approximately $100 \mu \mathrm{m}$ in length. The value seems to be higher than $17 \mu \mathrm{m}$ reported in the experimental work (Robertson $e t$ al. 1978). One possible reason for this larger plastic-zone size predicted in our model is the lack of multiple cracks formation in the current model, while, in reality, micro-cracks and natural imperfections inclusions in front of the crack tip may develop into mini cracks frontal that can release local stress concentration, thus, reducing the plastic-zone size.

\section{Microstructure-related difference in toughening mechanisms}

The damage scale factor denoted as STATUS in Fig. 6-d indicates that 1/3 of the crack surface is still under traction force and acts as toughening mechanisms that contributes to the non-linear fracture process. The toughening mechanisms active in a radial-transverse crack specimen can be divided predominantly into three types (Ritchie et al. 2005): (i) interfacial debonding as a result of the material's discontinuity at the interface between osteons and interstitial matrix - the formation of the weak path of cement line; (ii) crack diversion due to microstructural heterogeneity and material imperfections at which crack is redirected towards the most vulnerable part producing a twisted and deflected fracture path; (iii) uncracked-ligament bridging caused by osteon splitting and rupture acting as a post-crack toughening mechanism behind the crack tip. In this study, the microstructured models were able to capture these main features of the toughening mechanisms as shown in Fig. 7. Figure 7-d demonstrates an interface failure predicted by the model as the crack bends away from the osteon due to the discontinuity in the cement-line region. Figure 7 -e reveals the crack-diversion 
mechanism as crack deviates from its central line towards a vulnerable but twisted and deflected crack path. The uncracked-ligament bridging behind the crack tip is presented as a cohesive traction force between the damaged elements along the crack path (Fig. 7-f).

\section{Crack lengths analysis}

To investigate the effect of microstructural constituents on the crack propagation process, the crack length is plotted in Fig. 8 as a function of displacement of loading pin for the global model and three different sub-models. Their respective crack propagation paths are demonstrated in Fig. 9, row a. The total crack length was measured until reaching the maximum reaction force. It is clear from Fig. 8 that Model A has the longest overall crack length, while Model C has the shortest one. Comparing the respective crack trajectories, the higher crack length related to Model A is largely defined by significant crack deflections observed in Fig. 9-a. As a result of increase in the fractions of osteons and porosity from Model A to Model C, the effect of crack-deflection mechanism gradually reduces (Figs. 9 a, b and c). On the other hand, the crack-propagation rate (with respect to the loadingpin displacement) in Model $\mathrm{C}$ is higher at initial stage, but gradually reduces as the crack propagates through more Haversian systems, whereas Model B shows a moderate linear evolution process and Model A demonstrates an increased crackpropagation rate. It seems that an increased fraction of Haversian systems has a negative effect on the crack-propagation rate and constrains the crack-diversion magnitude. This finding is consistent with experimental observation in (Zimmermann et al. 2011), where the authors concluded that age-related changes in morphology of microstructure as a result of remodelling process may lead to suppression of the crack-deflection mechanism and reduction of the total crack length.

\section{Effect of cement line}

The effect of cement line was studied by changing the magnitude of its elastic modulus within the range $25 \%$ below and above that of osteon. The respective results for the crack propagation trajectory are compared in Fig. 9 for three different microstructural models. The result indicates that an increase in cement line's modulus to the levels equal to, or $25 \%$ higher than that of the osteon results 
in similar crack trajectories, that differ from the initial ones (i.e. for $25 \%$ lower modulus) for both Model A and Model B. This higher stiffness of cement line leads to some rise of fracture propagation in the regions with low fracture toughness - interstitial areas (Fig. 10). Moreover, higher stiffness also results in a higher rate of interface debonding in Model A and Model B (Figs. 9 b and c) where cement lines facilitate crack propagation around osteons. However, no substantial difference was found between the two groups (equal to and $25 \%$ higher). On the other hand, the lower cement modulus increase the chance of osteonal fracture and penetration into Haversian canal in Models A and B, where high fracture toughness and high compliance regions could potentially increase the overall fracture resistance and may lead to more crack deflections and arrests. As the osteon and porosity density increase in Model $\mathrm{C}$, the effect of the local heterogeneity becomes more dominant. Cracks are likely to grow along the most vulnerable path, and the effect of cement line relents. Therefore, the influence on the crack-propagation trajectory is less pronounced than in two other models. In summary, cement line plays an important role in the crack-propagation process in cortical bone. Variation of its mechanical properties can considerably affect the shape of local crack trajectory. Both scenarios demonstrated in our models have been widely discussed in previous research (Currey 2011; Ritchie et al. 2005). Considering the fact that bone is a dynamic living tissue, the mechanical properties of cement line are likely to vary with time and locations. It is thus sensible that a $25 \%$ differences in the cement line's modulus within the local area can cause both toughening and weakening mechanisms as observed in experiment (Chan and Nicolella 2012).

\section{Conclusions}

The fracture process in cortical bone was evaluated in this study based on the developed X-FEM models. Three models with different random microstructures were developed and imbedded into a homogeneous global model to investigate the effect of microstructural changes and the related varying local mechanical behaviour on the fracture propagation process in cortical bone. The results obtained in this study indicate that local changes in volume fractions of microstructural constituents have a significant effect on variability of the macroscopic fracture toughness. The developed microstructured models of 
cortical bone are able to represent accurately the non-uniform plastic deformation associated with the nonlinear fracture process as well as realization of distinct damage and fracture toughening mechanisms observed in experiments. Moreover, the use of different statistical realization of random microstructure demonstrated importance of the local heterogeneity on the fracture propagation process. Various crack propagation trajectories and crack lengths were observed with different microstructured bone models. The changes in the underlying microstructure of cortical bone and its mechanical properties result in different toughening mechanisms, that, in turn, affect the crack propagation process in a dissimilar manner. High volume fractions of osteons and porosity result in a smoother fracture surface as a result of a lack of crack-diversion mechanisms; the higher stiffness of cement line supresses the osteonal crack and facilitates the interstitial damage and interface debonding. The knowledge obtained through the development of these microstructured X-FEM models provides an additional insight into the micro-scale fracture process in cortical bone and might be used in the future to provide support and guidance for treatments against bone fracture.

\section{Acknowledgment}

The authors acknowledge the financial support from EPSRC UK (grant no. EP/G048886/1).

\section{References:}

Abdel-Wahab AA, Alam K, Silberschmidt VV. (2010a) Analysis of anisotropic viscoelastoplastic properties of cortical bone tissues. J Mech Behav Biomed Mater;4:807-820.

Adel A. Abdel-Wahab, Angelo R. Maligno and Vadim V. Silberschmidt. (2010b) Micro-scale numerical model of bovine cortical bone: Analysis of plasticity localization. 10th ASME Biennial Conference on Engineering Systems Design and Analysis. Istanbul, TURKEY.

Ascenzi A, Benvenuti A. (1986) Orientation of collagen fibers at the boundary between two successive osteonic lamellae and its mechanical interpretation. J Biomech;19:455-463.

Behiri JC, Bonfield W. (1989) Orientation dependence of the fracture mechanics of cortical bone. J Biomech;22:863-867, 869-872.

Bonney H, Colston BJ, Goodman AM. (2011) Regional variation in the mechanical properties of cortical bone from the porcine femur. Med Eng Phys;33:513-520.

Boyce TM, Fyhrie DP, Glotkowski MC, Radin EL, Schaffler MB. (2005) Damage type and strain mode associations in human compact bone bending fatigue. J Orthop Res;16:322-329.

Budyn E, Hoc T. (2007) Multiple scale modeling of cortical bone fracture in tension using X-

FEM. R E M N;16:213-236. 
Chan KS, Nicolella DP. (2012) Micromechanical modeling of R-curve behaviors in human Cortical Bone. J Mech Behav Biomed Mater;http://dx.doi.org/10.1016/j.jmbbm.2012.09.009.

Currey JD. (2011) The structure and mechanics of bone. J Mater Sci;47:41-54.

Currey JD. (1999) The design of mineralised hard tissues for their mechanical functions. J Exp

Biol;202:3285-3294.

Dassault Systèmes. (2012) Abaqus v6.12 Documentation-ABAQUS Analysis User's Manual. ABAQUS Inc;6.12.

Ebacher V, Wang R. (2008) A unique microcracking process associated with the inelastic deformation of haversian bone. Adv Funct Mater;19:57-66.

Ethier CR, Simmons CA. (2007) Introductory biomechanics: from cells to organisms. Cambridge Univ Pr New York.

Fratzl P, Gupta HS, Paschalis EP, Roschger P. (2004) Structure and mechanical quality of the collagen-mineral nano-composite in bone. J Mater Chem;14:2115-2123.

Li S, Abdel-Wahab A, Silberschmidt VV. (2012) Analysis of fracture processes in cortical bone tissue. Eng Fract Mech:http://dx.doi.org/10.1016/j.engfracmech.2012.11.020.

Liu D, Weiner S, Daniel Wagner H. (1999) Anisotropic mechanical properties of lamellar bone using miniature cantilever bending specimens. J Biomech;32:647-654.

X. C. Liu, X. Qin and Z. Du. (2010) Bone fracture analysis using the extended finite element method (XFEM) with abaqus. The 34th Annual Meeting of the American Society of Biomechanics. 2010. Brown University.

Martin RB, Boardman DL. (1993) The effects of collagen fiber orientation, porosity, density, and mineralization on bovine cortical bone bending properties. J Biomech;26:1047-1054.

Montalbano T, Feng G. (2011) Nanoindentation characterization of the cement lines in ovine and bovine femurs. J Mater Res;26:1036-1041.

Nalla RK, Kruzic JJ, Ritchie RO. (2004) On the origin of the toughness of mineralized tissue: microcracking or crack bridging? Bone;34:790-798.

Nalla RK, Kinney JH, Ritchie RO. (2003) Mechanistic fracture criteria for the failure of human cortical bone. Nature materials;2:164-168.

Nalla RK, Kruzic JJ, Kinney JH, Ritchie RO. (2005) Mechanistic aspects of fracture and R-curve behavior in human cortical bone. Biomater;26:217-231.

Nyman JS, Leng H, Dong XN, Wang X. (2009) Differences in the mechanical behavior of cortical bone between compression and tension when subjected to progressive loading. J Mech Behav Biomed Mater;2:613-619.

Peterlik H, Roschger P, Klaushofer K, Fratzl P. (2006) Orientation dependent fracture toughness of lamellar bone. Int J Fract;139:395-405.

Piccolroaz A, Mishuris G, Movchan A, Movchan N. (2012) Perturbation analysis of Mode III interfacial cracks advancing in a dilute heterogeneous material. Int J Solids Structures;49:244-255. Ritchie RO, Kinney JH, Kruzic JJ, Nalla RK. (2005) A fracture mechanics and mechanistic approach to the failure of cortical bone. Fatigue Fract Engng Mater Struct;28:345-371.

Robertson DM, Robertson D, Barrett CR. (1978) Fracture toughness, critical crack length and plastic zone size in bone. J Biomech;11:359-364. 
Ural A, Vashishth D. (2006) Cohesive finite element modeling of age-related toughness loss in human cortical bone. J Biomech;39:2974-2982.

Ural A, Zioupos P, Buchanan D, Vashishth D. (2011) The effect of strain rate on fracture

toughness of human cortical bone: A finite element study. J Mech Behav Biomed Mater;4:10211032.

Vashishth D, Tanner KE, Bonfield W. (2003) Experimental validation of a microcracking-based toughening mechanism for cortical bone. J Biomech;36:121-124.

Yang QD, Cox BN, Nalla RK, Ritchie RO. (2006) Fracture length scales in human cortical bone: the necessity of nonlinear fracture models. Biomater;27:2095-2113.

Zimmermann EA, Schaible E, Bale H, Barth HD, Tang SY, Reichert P et al. (2011) Age-related changes in the plasticity and toughness of human cortical bone at multiple length scales. Proc Nati Ac Sci;108:14416-14421.

Zioupos P, Currey JD. (1994) The extent of microcracking and the morphology of microcracks in damaged bone. J Mater Sci;29:978-986.

Zioupos P, Wang X, Currey JD. (1996) The accumulation of fatigue microdamage in human cortical bone of two different ages in vitro. Clin Biomech;11:365-375. 


\section{Figure captions:}

Figure 1 Schematic illustration of model configuration for the three-point-bending setup using global model and microstructured sub-model

Figure 2 Schematic illustration of specimen, image of real microstructure, Cumulative distribution functions and three statistical realizations of random microstructures with different fractions of constituents for three submodels

Figure 3 Mesh convergence study; mesh sizes varied from $500 \mu \mathrm{m}$ to $30 \mu \mathrm{m}$

Figure 4 Comparison of experimental (Li et al. 2012) force - displacement diagram with results for different FE models (error bar indicates variations of experimental results)

Figure 5 Comparison of proportions of energy associated with plastic deformation for different models

Figure 6 Contour plots for von-Mises stress (a), maximum principal strain (b), equivalent plastic strain (PEEQ) (c) and damage scale factor for X-FEM (STATUS) (d) for Model B for crack propagation approaching for maximum reaction force ((a) and (b) represent full Model B)

Figure 7 Comparison of toughening mechanisms in radial-transverse crack plane between experimental results (a,b and c) and numerical simulations (d, e and f): (a and d) interface failure between osteon and interstitial matrix; ( $b$ and e) crack deviation from its central line towards vulnerable but twisted and deflected crack path as a result of material heterogeneity; ( $\mathrm{c}$ and $\mathrm{f}$ ) splitting of osteons and breakage of ligament due to crack opening observed in SEM image (c) Figure 8 Crack length - displacement diagram for global and microstructured models (the total crack length is measured until reaching the maximum reaction force)

Figure 9 Crack propagation trajectories for various elastic moduli of cement line for three microstructured models: row (a): $25 \%$ lower than that of osteon; row (b): equal to that of osteon; row (c): $25 \%$ higher than that of osteon

Figure 10 Fractions of crack path in microstructure constituents for various magnitudes of cement line's modulus 
Table captions:

Table 1 Volume fractions of microstructure constituents for Models A, B and C

Table 2 Material properties used in global model and microstructured submodels (Budyn and Hoc 2007; Katz et al. 1984; Abdel-Wahab et al. 2010b; Ritchie et al. 2005) 


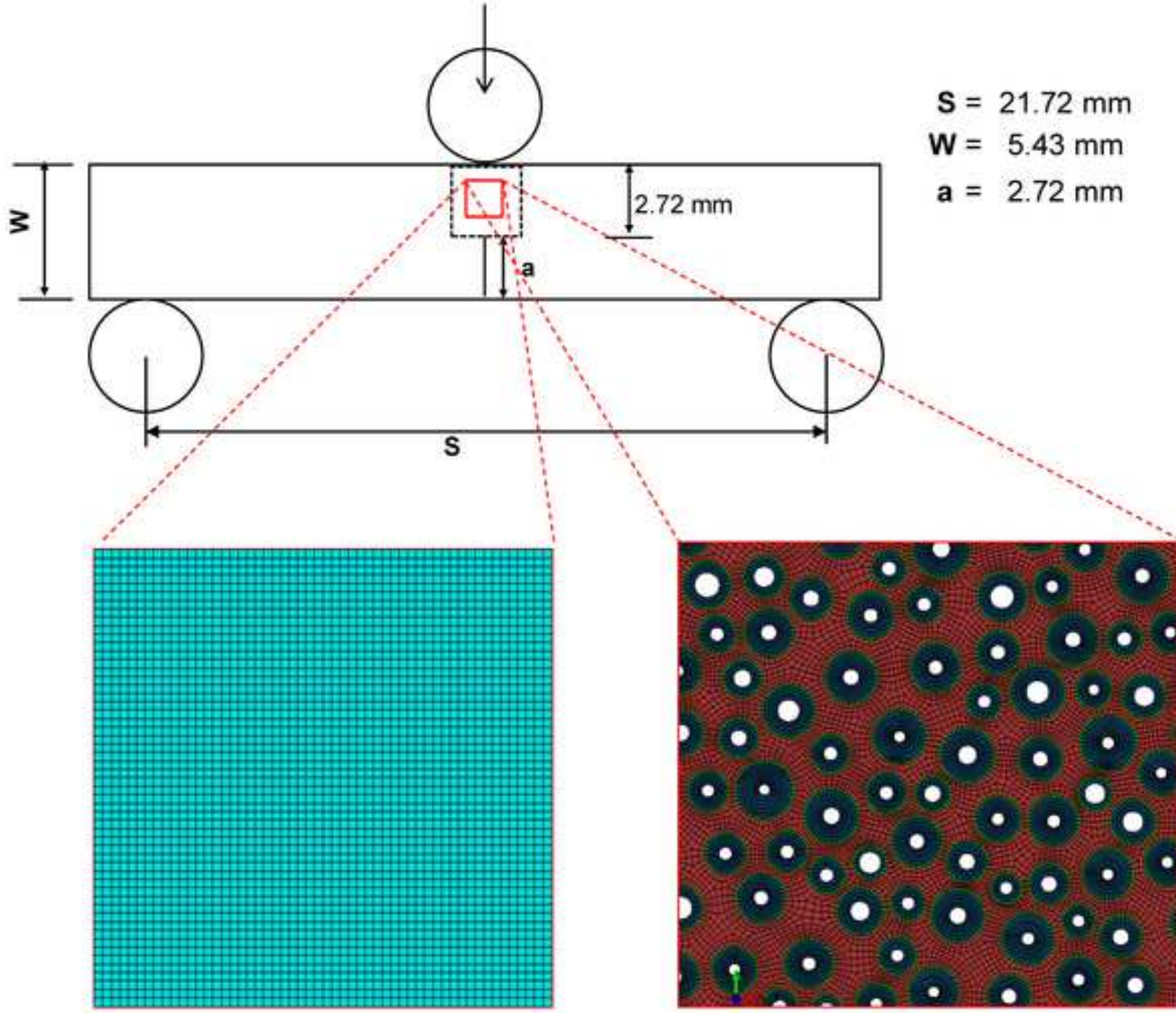

Global-model mesh

Sub-model mesh 


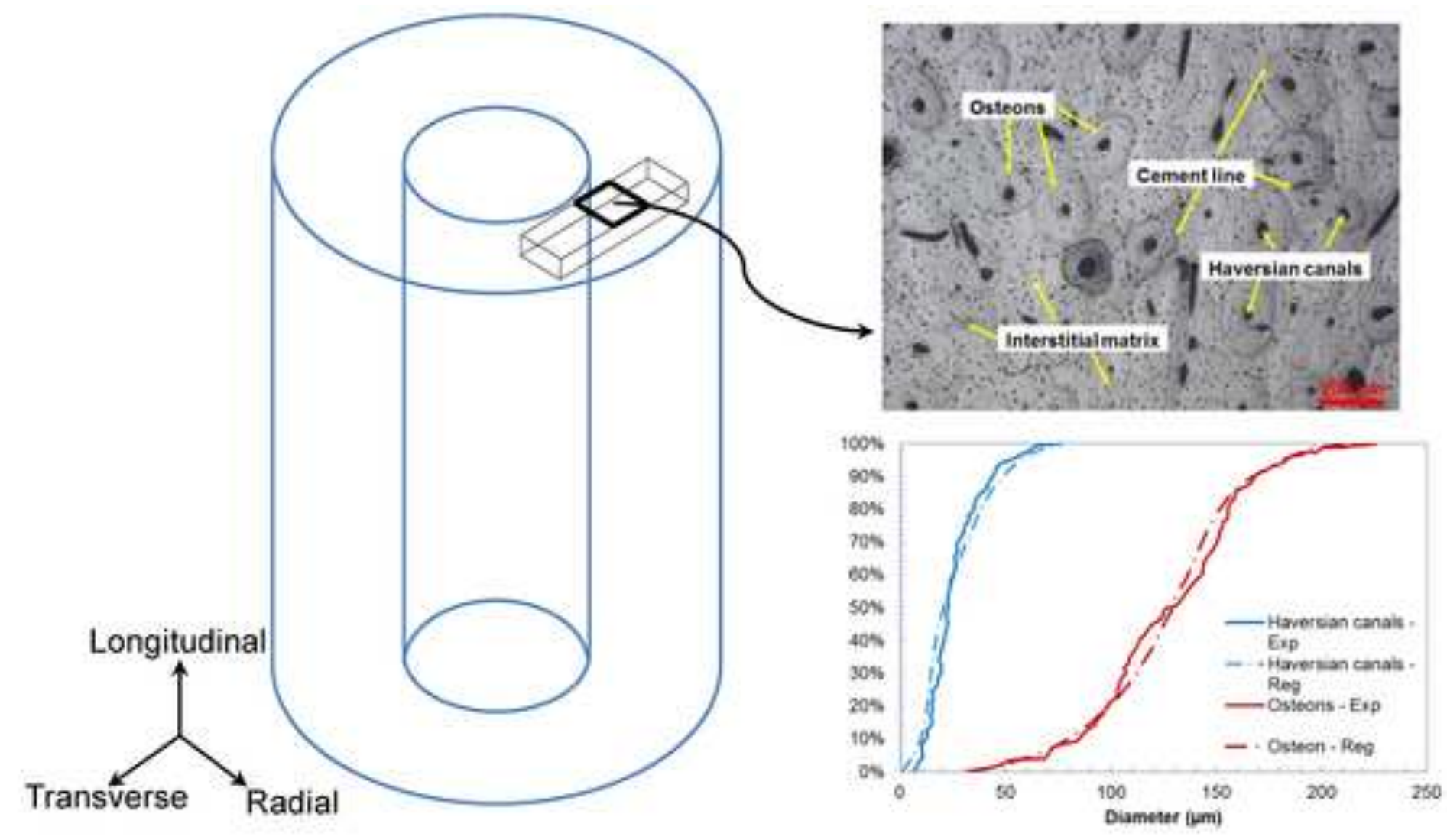

Model A

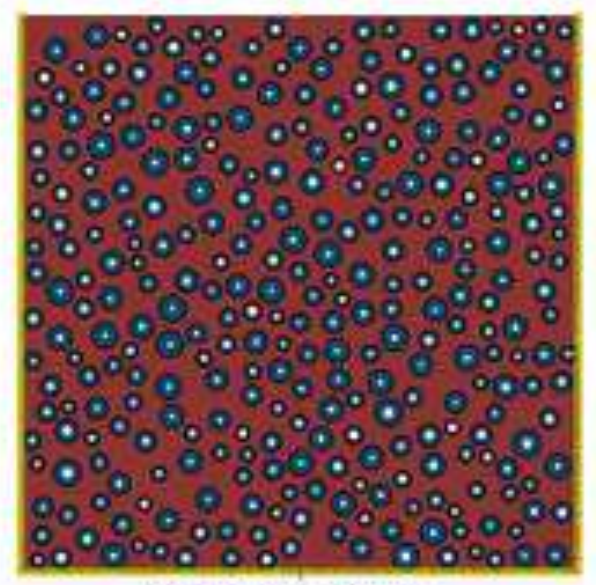

Osteon: $30 \%$

Porosity: $5 \%$
Model B

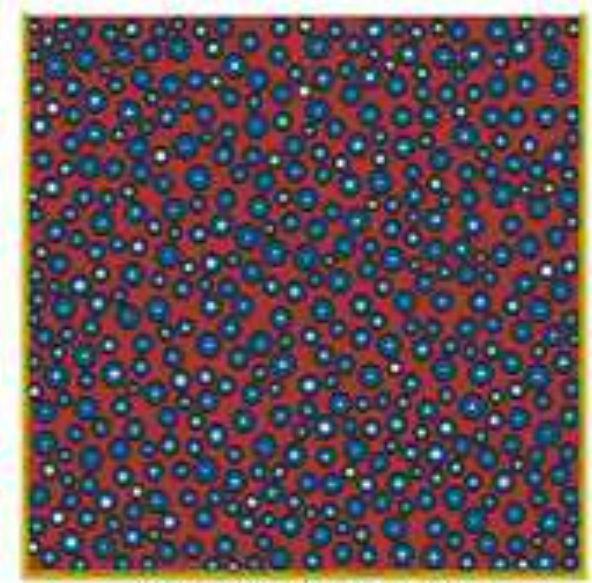

Osteon: $44.5 \%$

Porosity: $5 \%$
Model C

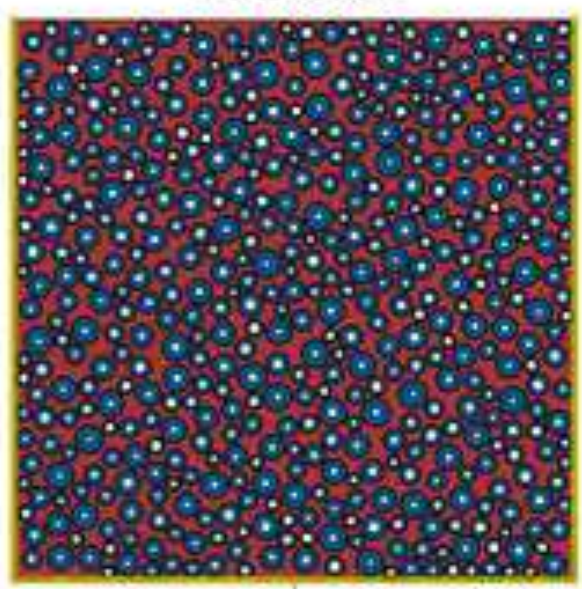

Osteon: $51 \%$

Porosity: $8.14 \%$ 


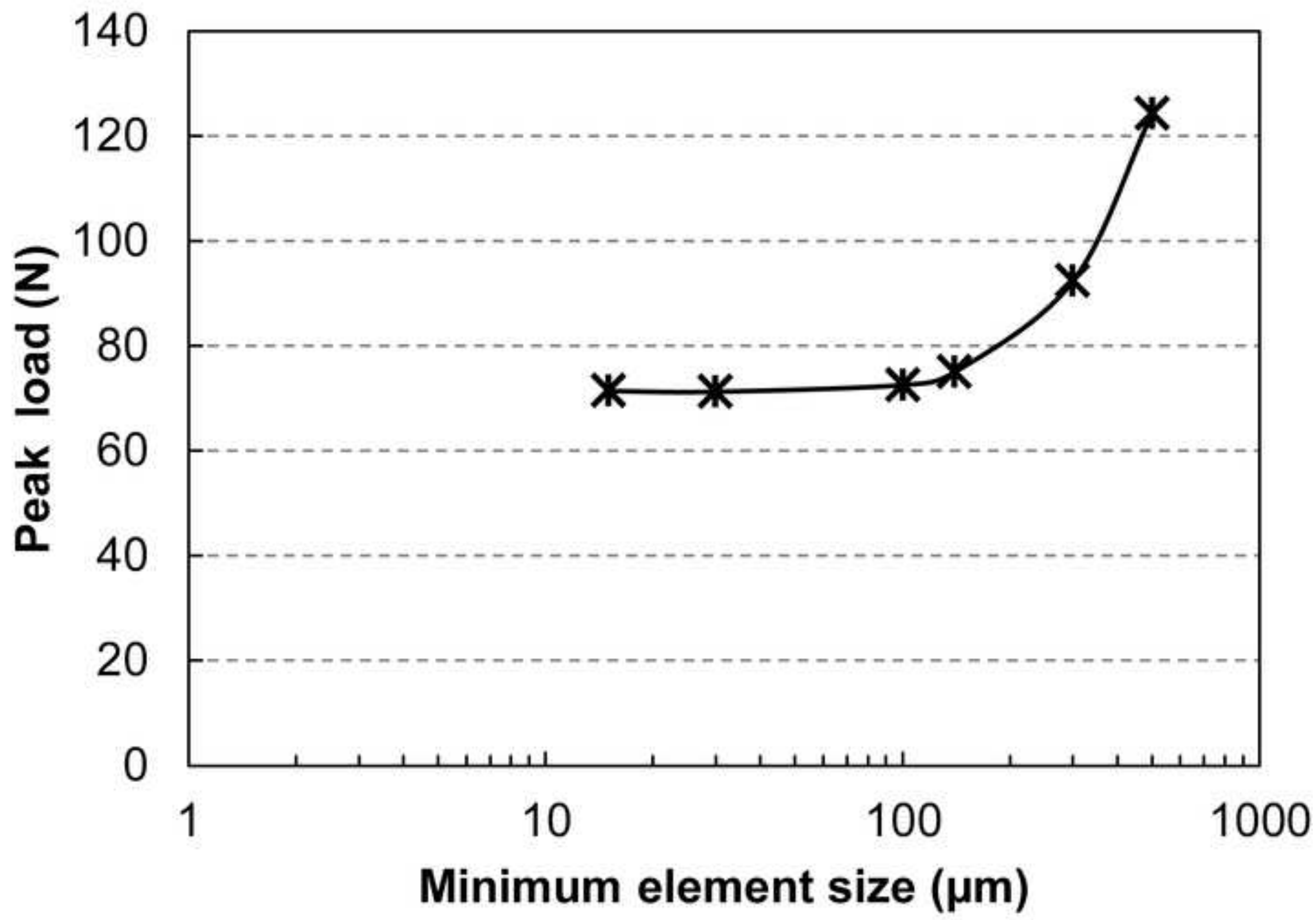




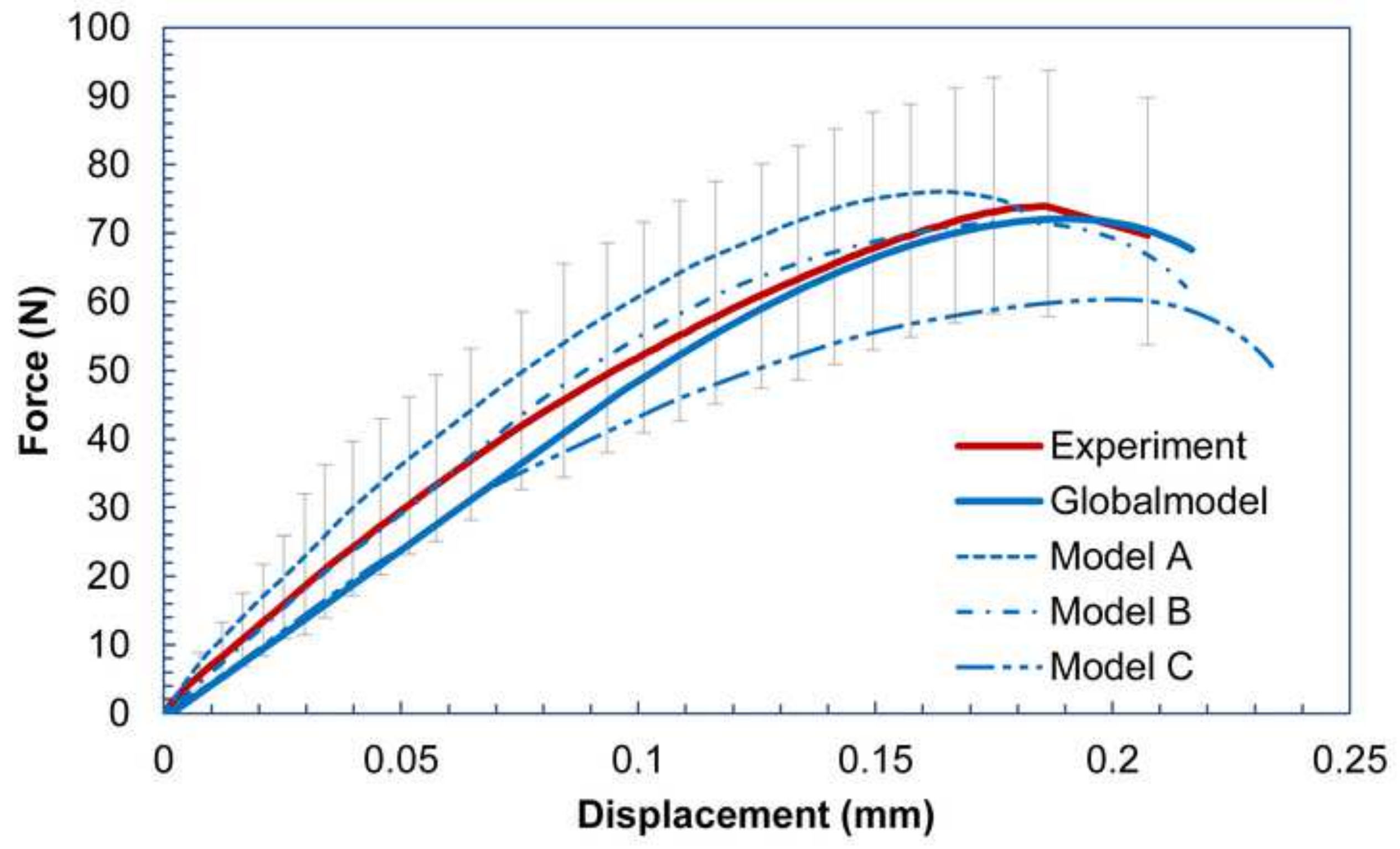




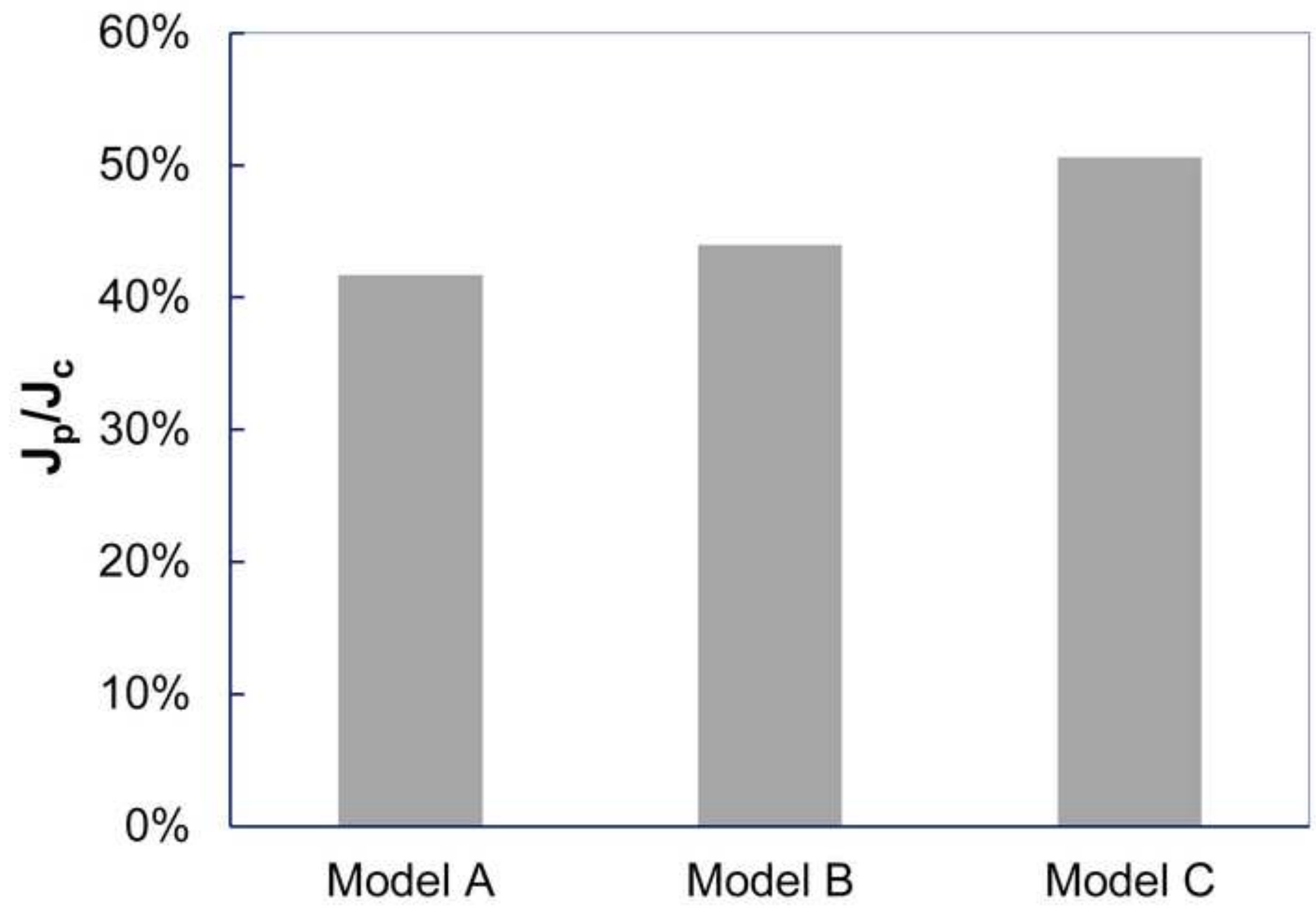


Loading Pin
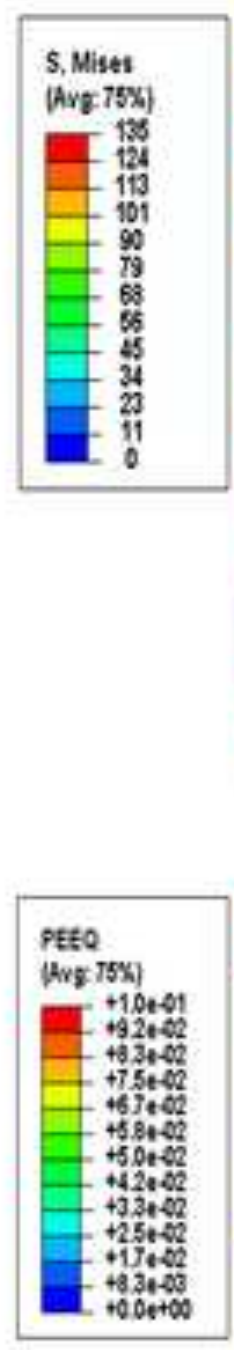
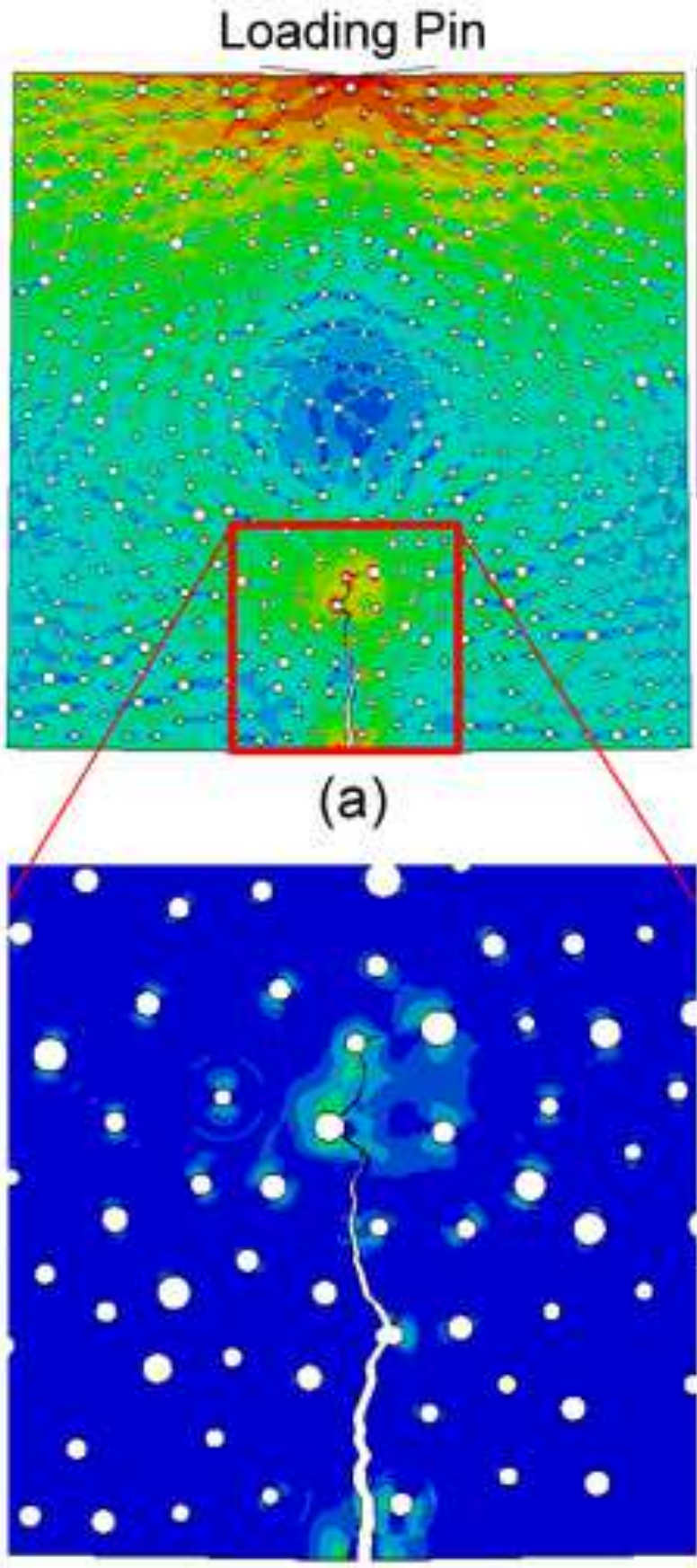

(c)
Loading Pin

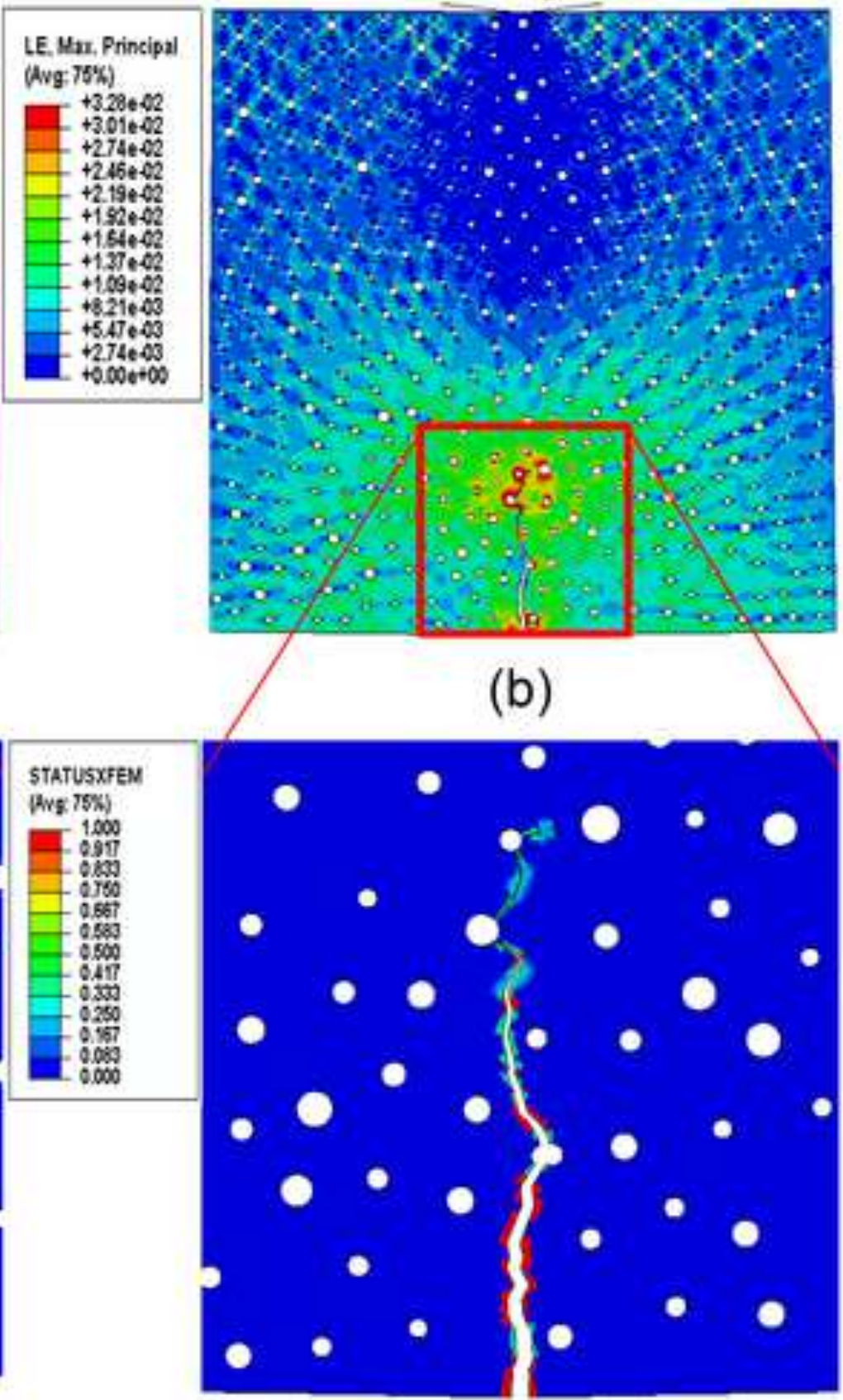

(d) 

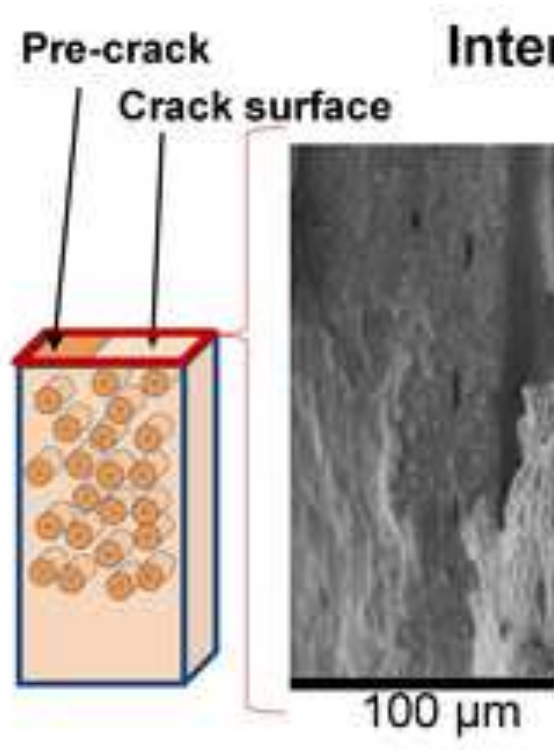

Interface failure

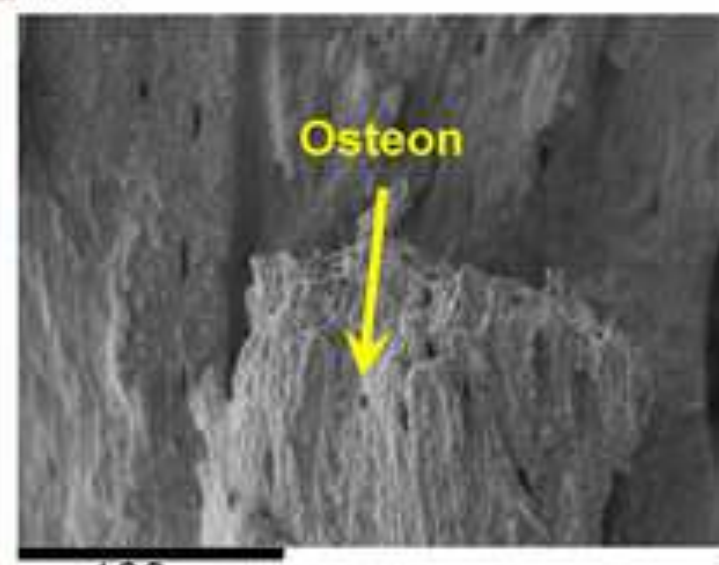

(a)

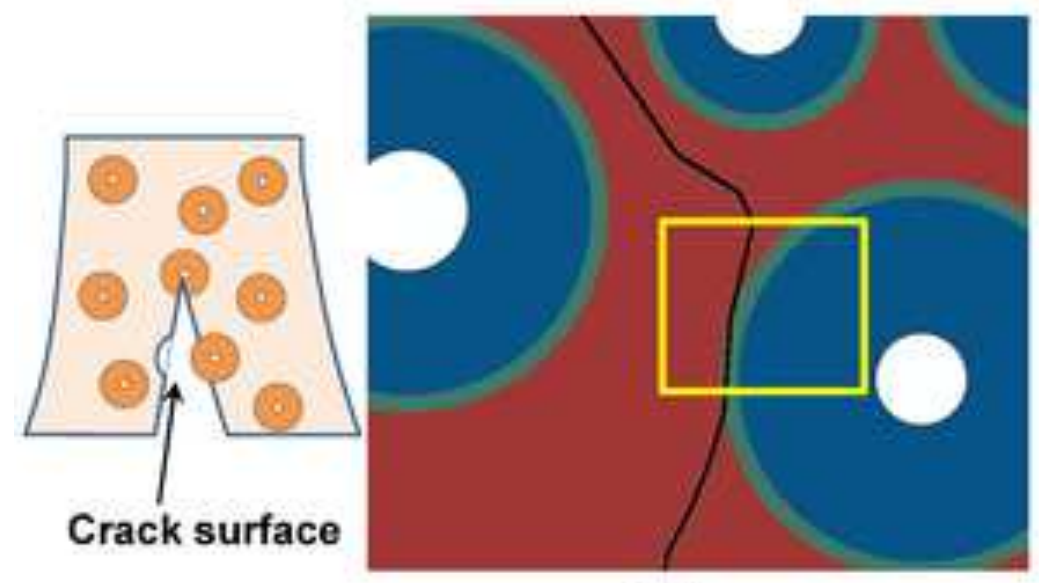

(d)
Crack diversion

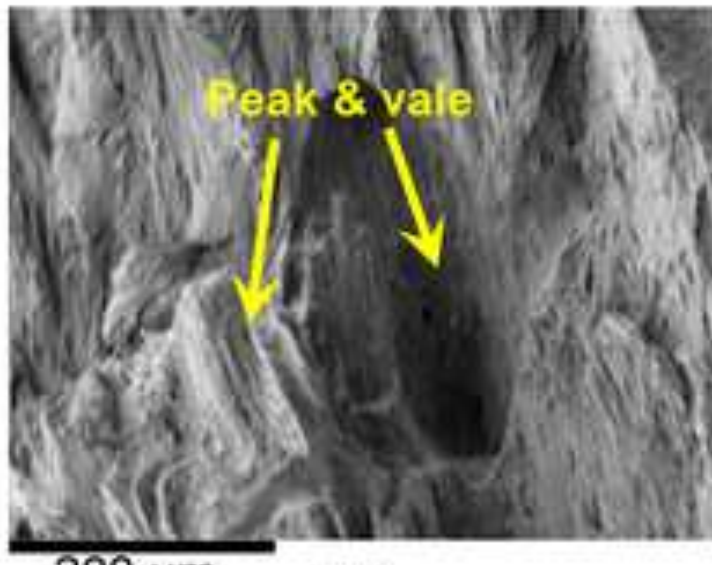

(b)

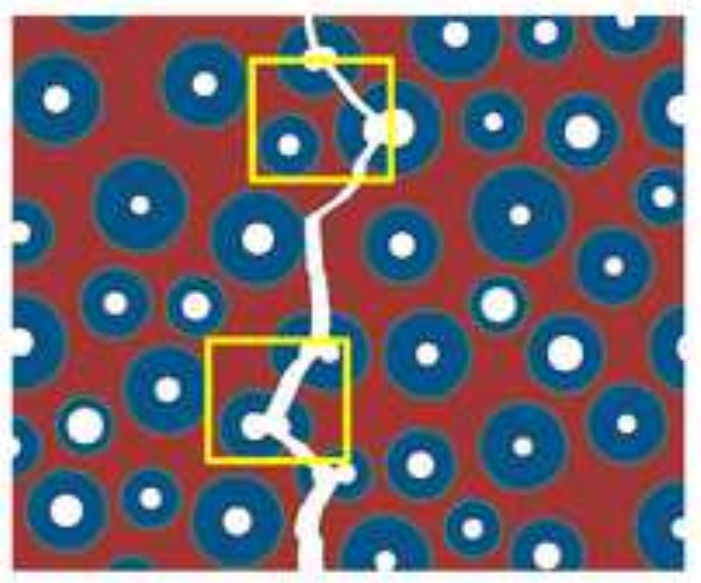

(e)
Splitting \& rupture

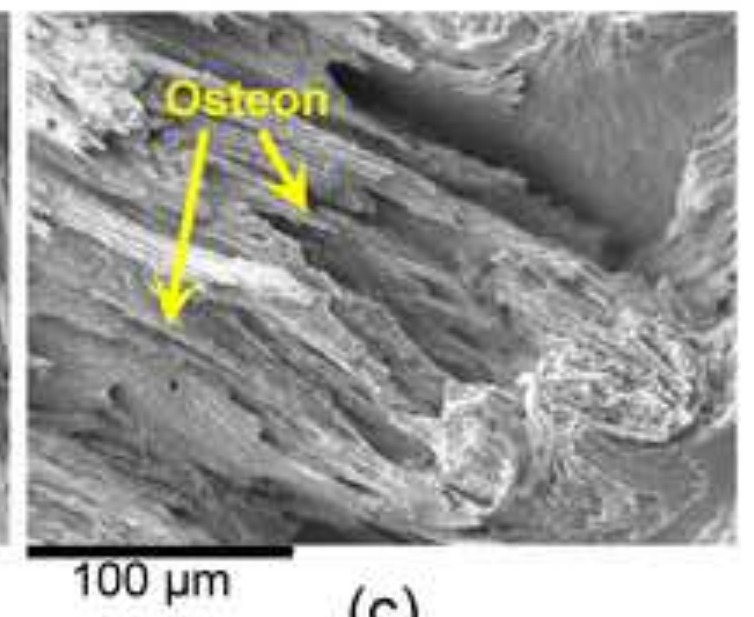

(c)

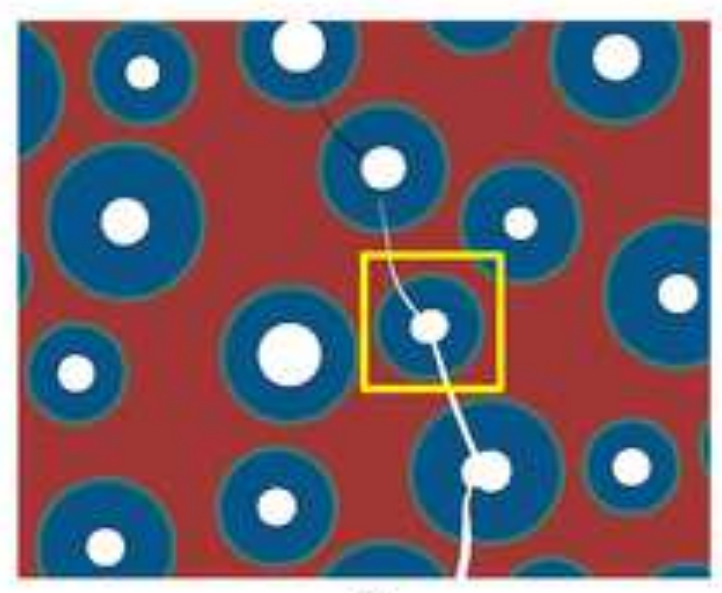

(f) 


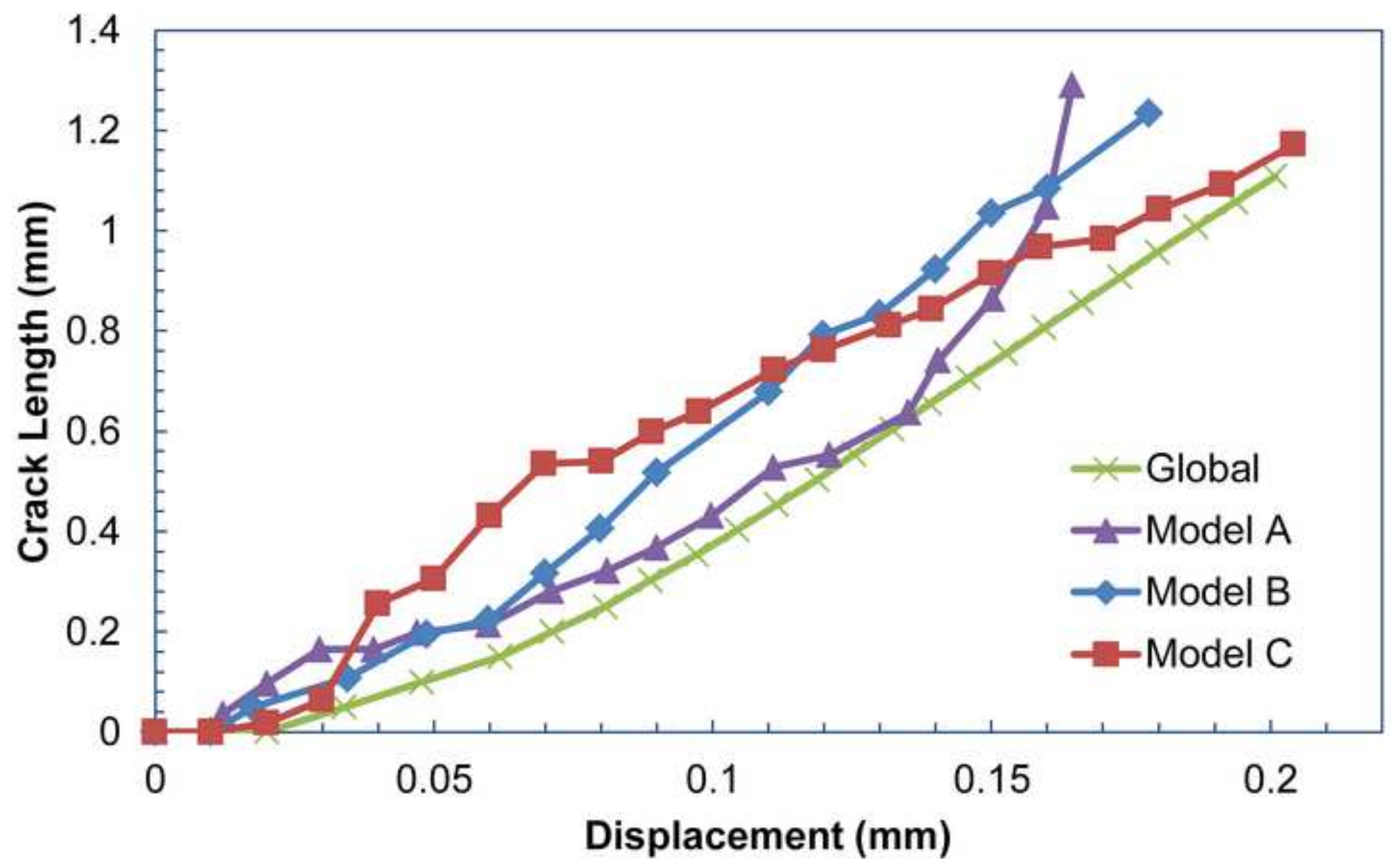




\section{Model A}

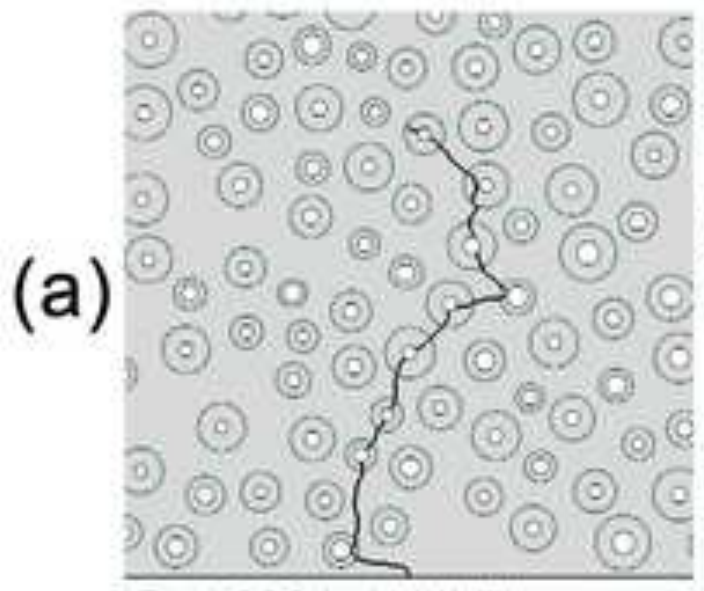

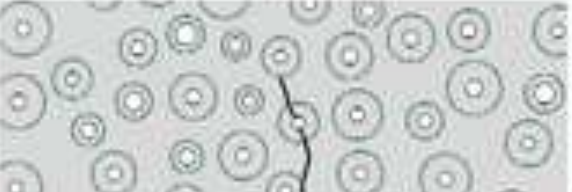

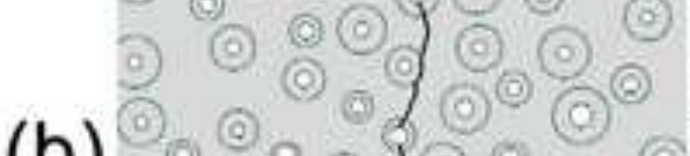

(b)

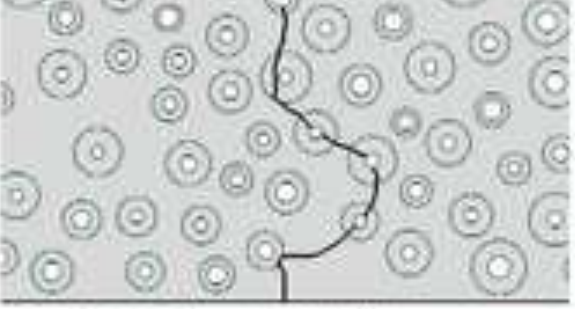

(0)

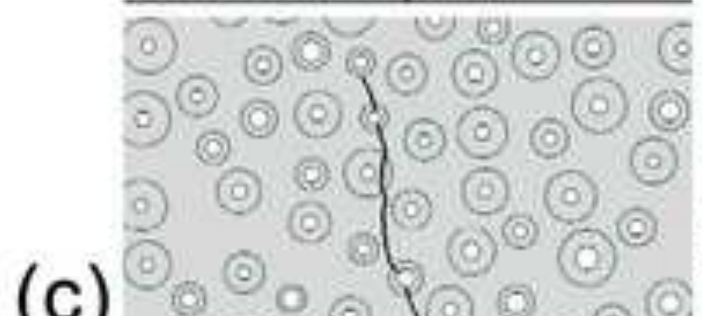

(c)

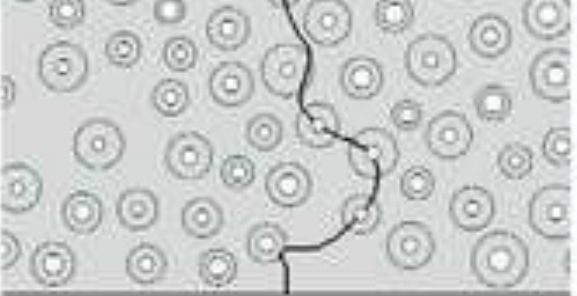

\section{Model B}

Model C
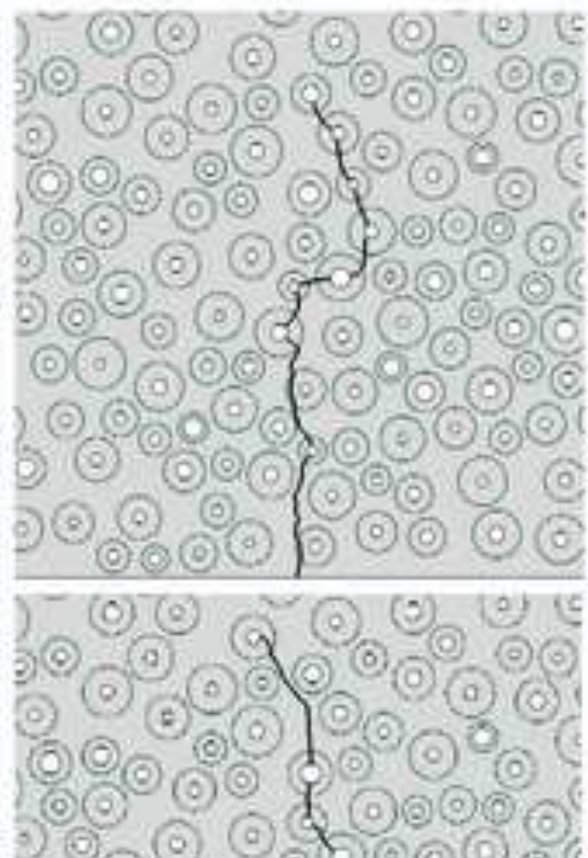
(9) (0) (a) (0) (c) (c) 9) (9) (9) 9 (9)

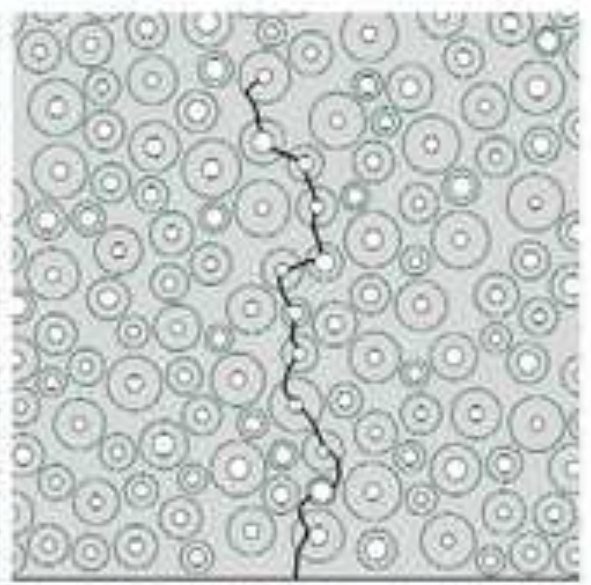

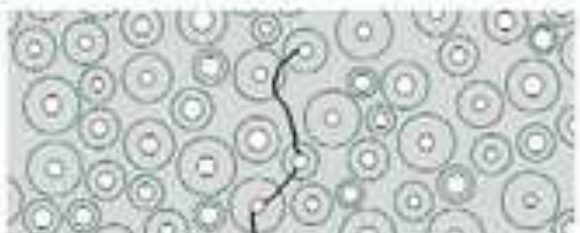

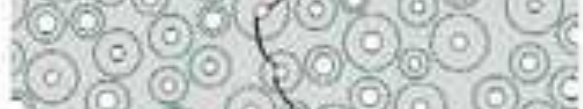
(O) (o) (o) 30 (9) 6 (6) (9) 0 (0) $9(0)(0)$ (8) (9) (9) (6) $(0)(0)(0)(0)$

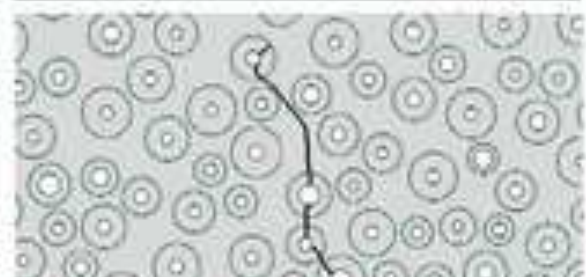
9 (0) $(0)(0)$

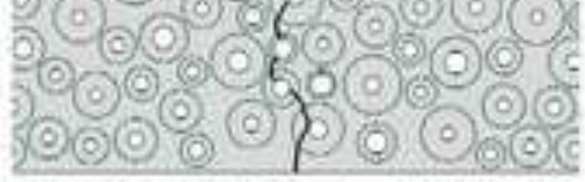
(o) (0) (0)

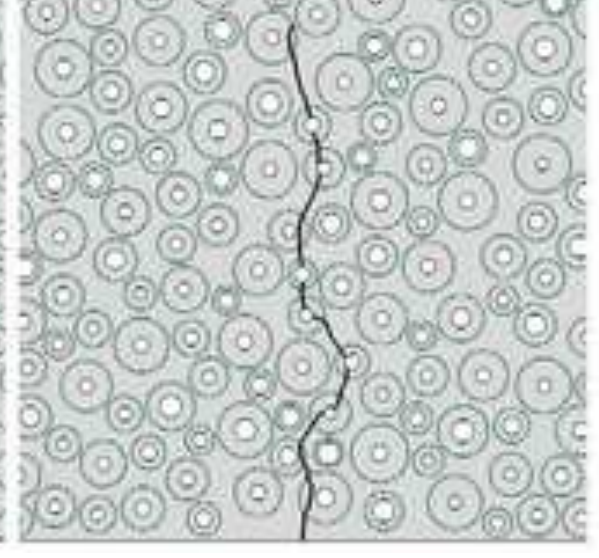


Model A

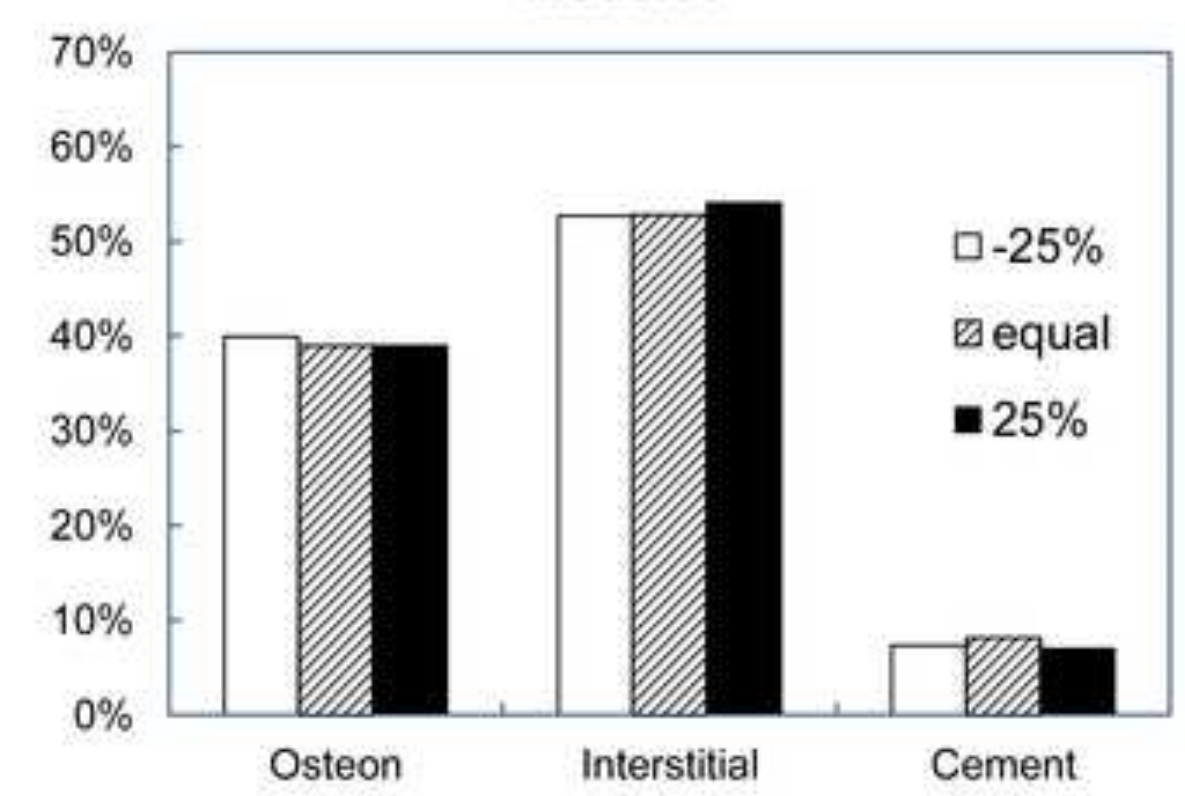

Model B Model C
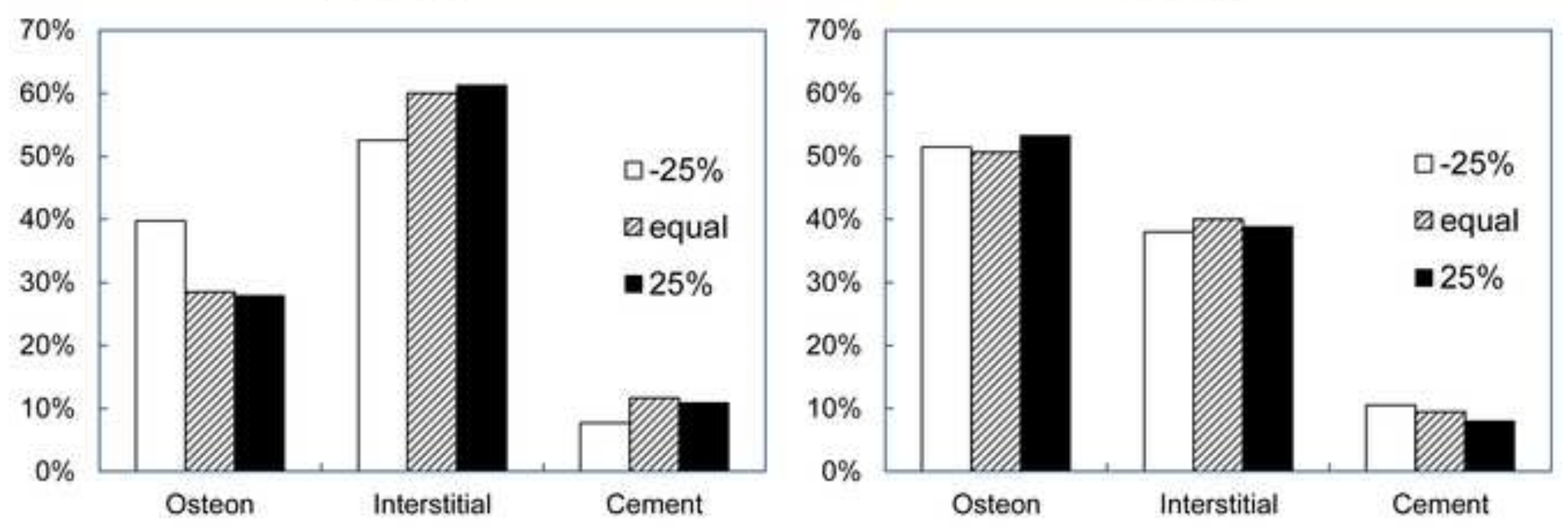


\begin{tabular}{cccc}
\hline Constituent & Model A & Model B & Model C \\
\hline Osteon & $30 \%$ & $44.5 \%$ & $51.2 \%$ \\
Porosity & $5.01 \%$ & $5.02 \%$ & $8.14 \%$ \\
Interstitial matrix & $58.77 \%$ & $41.25 \%$ & $30.04 \%$ \\
Cement Line & $6.22 \%$ & $9.23 \%$ & $10.62 \%$ \\
\hline
\end{tabular}




\begin{tabular}{ccccc}
\hline & $\begin{array}{c}\text { Effective } \\
\text { homogenised } \\
\text { material }\end{array}$ & Osteons & $\begin{array}{c}\text { Interstitial } \\
\text { matrix }\end{array}$ & $\begin{array}{c}\text { Cement } \\
\text { line }\end{array}$ \\
\hline $\begin{array}{c}\text { Elastic modulus } \\
(\mathrm{GPa})\end{array}$ & 11.18 & 12.85 & 14.12 & 9.64 \\
$\begin{array}{c}\text { Poisson's ratio } \\
\text { Yield strain }\end{array}$ & 0.167 & 0.17 & 0.153 & 0.49 \\
$\begin{array}{c}\text { Fracture initiation } \\
\text { strain }\end{array}$ & $0.6 \%$ & $0.6 \%$ & $0.6 \%$ & $0.6 \%$ \\
$\begin{array}{c}\text { Fracture energy } \\
\text { release rate } \\
(\mathrm{N} / \mathrm{m})\end{array}$ & $0.65 \%$ & $0.65 \%$ & $0.65 \%$ & $0.65 \%$ \\
\hline
\end{tabular}

